\title{
MRI Evaluation of Paraspinal Muscle Fatty Infiltration in Low Back Pain Patients
}

\author{
Tirza Dian Patricia Lintang, Paulus Rahardjo*, Rosy Setiawati \\ paulus.r.rahardjo@gmail.com \\ ${ }^{a}$ Radiology Department, Faculty of Medicine, Universitas Airlangga, Surabaya, Indonesia \\ ${ }^{b}$ Musculoskeletal consultant, Radiology Department, Faculty of Medicine, Universitas Airlangga, Surabaya, Indonesia
}

\begin{abstract}
Low back pain (LBP) is a leading cause of disability in working age adults. Several studies suggested that the role of paraspinal muscles in LBP. The paraspinal muscles demonstrated some degree intramuscular fatty infiltration as a form of atrophy. This is a study to assess the paraspinal muscles fatty infiltration from lumbosacral MRI in patients with acute and chronic LBP. Total sample of 52 LBP patients, with exclusion criterias as history of trauma, infection, spine surgery, malignancy, bedridden for at least 1 week within the last 12 months, immunodeficiency, sepsis, burn, congestive heart failure, chronic renal disease, and history of liver, gallbladder, or pancreatic disease. The grading assessment were using Goutallier classification, a reliable tool to assess fatty infiltration grade in erector spinae, multifidus, and psoas major. The result showed that acute LBP patients $(n=23)$ have lower maximum grade of fatty infiltration (grade 1 in erector spinae; grade 2 in multifidus and psoas major). While the chronic LBP patients $(n=29)$ have higher maximum grade of fatty infiltration. We also found that the lowest level tends to showed higher grade of fatty infiltration in all three muscles. However, it needs a further study to evaluate association between duration and grade of fatty infiltration, or to determine whether the fatty infiltration occurred before LBP or vice versa.
\end{abstract}

Published by IJRP.ORG. Selection and/or peer-review under responsibility of International Journal of Research Publications (IJRP.ORG)

Keywords: Low Back Pain; Paraspinal Muscle, Fatty Infiltration, MRI

\section{Introduction}

Low back pain (LBP) is defined as pain, muscle tension, or stiffness localized below the costal margin and above the inferior gluteal fold, with or without sciatica. (Kalichman, Carmeli and Been, 2017) It as a health problem affecting 11-84\% adults in their lifetime (Sitthipornvorakul et al., 2011; Hildebrandt et al., 2017), and has become the leading cause of disability in adults of working age. (Bhadresha, Lawrence and McCarthy, 2016)

Several studies have shown the role of paraspinal muscles in etiology of LBP. The studies suggested that atrophy and intramuscular fatty infiltration of paraspinal muscles has been demonstrated in patients with LBP. (Kjaer et al., 2007; Wan et al., 2015) Several theories also suggest that degenerative changes, which is also caused LBP, can cause nerve root compression and denervation of paraspinal muscle (multifidus), leading a severe and greatest reduction of the muscle. (Wan et al., 2015) While the paraspinal muscles can be assessed using computed tomography, ultrasound, and magnetic resonance imaging (MRI) (Kalichman, Carmeli and Been, 2017), MRI is more superior due to the capability to evaluates muscle composition with good soft-tissue contrast and radiation free. (Wan et al., 2015)

Despite the many studies conducted to enhance our knowledge of this issue, most studies focused on comparing the paraspinal muscles cross-sectional area (CSA) of chronic LBP patients with healthy subjects. (Danneels et al., 2000; 
Beneck and Kulig, 2012; Fortin and Macedo, 2013) This study aims to evaluate the grade of fatty infiltration in paraspinal muscles from MRI examination of acute and chronic LBP patients.

\section{Method}

\subsection{Subjects}

The sample consisted of 52 patients with low back pain underwent lumbosacral MRI examination in Radiology Department of Soetomo General Academic Hospital Surabaya. The participants were at least 30 years of age with acute (less than 12 weeks) duration or chronic (at least 12 weeks) duration LBP. The exclusion criteria were history of trauma, infection, spine surgery, malignancy, bedridden for at least 1 week within the last 12 months, immunodeficiency, sepsis, burn, congestive heart failure, chronic renal disease, and history of liver, gallbladder, or pancreatic disease.

This study was approved in Ethics Committee of Soetomo General Academic Hospital, Surabaya (1605/KEPK/X/2019).

\subsection{MRI and Fatty Infiltration Grading}

The lumbosacral MRI examinations in this study were done according to standards protocol, performed at either 1.5T or 3T MRI. The MRI axial images with sagittal cross-references were made at three levels along the lumbar spine (L3-L4, L4-L5, and L5-S1) in T2 weighted image. Two musculoskeletal radiologists then analyze the fat infiltration in three muscles (erector spinae, multifidus, and psoas major) in each level, using the Goutallier classification.

The grading system divided into 5 criterias:

- $\quad$ grade $0:$ no fatty infiltration;

- grade 1 : fatty streaks within the muscle;

- $\quad$ grade 2 : fat less than muscle;

- grade 3 : fat and muscle equal;

- $\quad$ grade 4 : fat greater than muscle.

The Goutallier classification is a reliable tool to grade the fatty infiltration. (Battaglia et al., 2014).

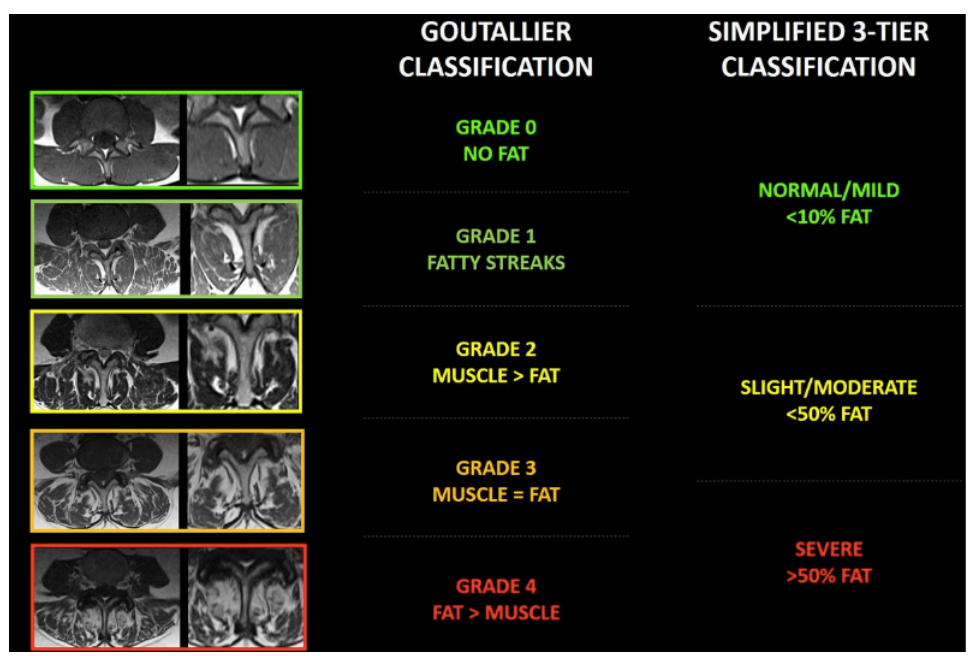

Figure 1. Goutallier and simplified 3-tier classification. (Upadhyay and Toms, 2015) 


\subsection{Statistical Analysis}

We use SPSS24 software (IBM, Armonk, New York, United States) for statistical analysis. Data from demographic and fatty infiltration grading were arranged in table and analyzed.

\section{Results}

The final sample size that met the inclusion and exclusion criteria was 52 patients. The mean age was $54.0 \pm 9.8$ years(range $31-79$, most patients are at the age range of 41-60 $(\mathrm{n}=38,73.1 \%)$ and $34(65.4 \%)$ were female. Acute LBP was found in 23 patients (44.2\%), while the other 29 patients (55.8\%) have chronic LBP (Table 1$)$.

The grade of fatty infiltration of paraspinal muscles, the data shown on table 2 and 3 are grades of fatty infiltration in paraspinal muscles divided into acute and chronic onset of LBP. Table 2 showed that in acute LBP patients ( $\mathrm{n}=23)$ the fatty infiltration grades ranged from minimal grade of 0 to maximum grade of 1 in erector spinae muscles; and maximum grade of 2 in multifidus and psoas major muscles. The grades are also higher in the lowest level of evaluation (L5-S1) in all three muscles. The chronic LBP patients $(\mathrm{n}=29)$ as shown in table 3, have higher maximum grade of fatty infiltration with higher maximum gradein all muscles. The grades also showed increased of fatty infiltration of all three muscles in level L5-S1.

Table 1. Demographic and LBP onset of participating patients

\begin{tabular}{lll}
\hline Profile & $\mathrm{n}$ & $\%$ \\
\hline Sex & & \\
Male & 18 & $34.6 \%$ \\
Female & 34 & $65.4 \%$ \\
Age (years) & & \\
$31-40$ & 3 & $5.8 \%$ \\
$41-60$ & 38 & $73.1 \%$ \\
$61-80$ & 11 & $21.2 \%$ \\
Onset & & \\
Acute & 23 & $44.2 \%$ \\
Chronic & 29 & $55.8 \%$ \\
\hline
\end{tabular}

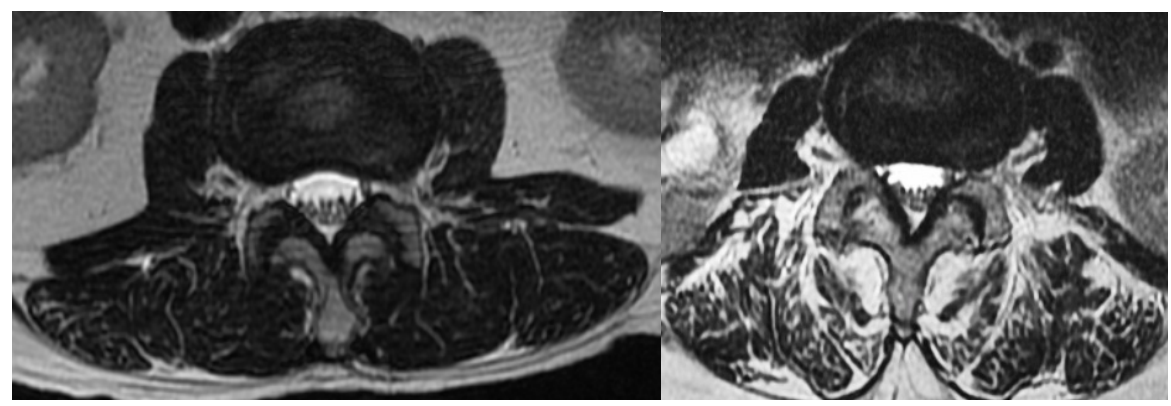

Figure 2. Axial image of paraspinal muscles in acute LBP patient (a) and chronic LBP patient (b). 
Table 2. Grade of Fatty Infiltration in Acute LBP patient

\begin{tabular}{|c|c|c|c|c|c|c|c|c|}
\hline \multirow{2}{*}{ Muscle And Level } & \multicolumn{5}{|c|}{ Grade of fatty infiltration ( $\mathrm{n}$ of samples) } & \multirow[t]{2}{*}{ Min. Grade } & \multirow[t]{2}{*}{ Max.Grade } & \multirow[t]{2}{*}{ Mean (SD) } \\
\hline & 0 & 1 & 2 & 3 & 4 & & & \\
\hline \multicolumn{9}{|l|}{ Erector spinae L3-4 } \\
\hline Right & 16 & 7 & 0 & 0 & 0 & 0 & 1 & $0.30( \pm 0.47)$ \\
\hline Left & 16 & 7 & 0 & 0 & 0 & 0 & 1 & $0.30( \pm 0.47)$ \\
\hline
\end{tabular}

Erector spinae L4-5

$\begin{array}{lllllllll}\text { Right } & 15 & 8 & 0 & 0 & 0 & 0 & 1 & 0.34( \pm 0.48) \\ \text { Left } & 15 & 8 & 0 & 0 & 0 & 0 & 1 & 0.34( \pm 0.48)\end{array}$

Erector spinae L5-S1

$\begin{array}{lllllllll}\text { Right } & 13 & 10 & 0 & 0 & 0 & 0 & 1 & 0.43( \pm 0.50) \\ \text { Left } & 13 & 10 & 0 & 0 & 0 & 0 & 1 & 0.43( \pm 0.50)\end{array}$

Multifidus L3-4

$\begin{array}{lllllllll}\text { Right } & 14 & 8 & 1 & 0 & 0 & 0 & 2 & 0.43( \pm 0.58) \\ \text { Left } & 14 & 8 & 1 & 0 & 0 & 0 & 2 & 0.43( \pm 0.58)\end{array}$

Multifidus L4-5

$\begin{array}{lllllllll}\text { Right } & 13 & 8 & 2 & 0 & 0 & 0 & 2 & 0.52( \pm 0.66) \\ \text { Left } & 13 & 8 & 2 & 0 & 0 & 0 & 2 & 0.52( \pm 0.66)\end{array}$

Multifidus L5-S1

$\begin{array}{lllllllll}\text { Right } & 11 & 10 & 2 & 0 & 0 & 0 & 2 & 0.60( \pm 0.65) \\ \text { Left } & 11 & 10 & 2 & 0 & 0 & 0 & 2 & 0.60( \pm 0.65)\end{array}$

Psoas major L3-4

$\begin{array}{lllllllll}\text { Right } & 16 & 6 & 1 & 0 & 0 & 0 & 2 & 0.34( \pm 0.57) \\ \text { Left } & 16 & 6 & 1 & 0 & 0 & 0 & 2 & 0.34( \pm 0.57)\end{array}$

Psoas major L4-5

$\begin{array}{lllllllll}\text { Right } & 14 & 8 & 1 & 0 & 0 & 0 & 2 & 0.43( \pm 0.58) \\ \text { Left } & 14 & 8 & 1 & 0 & 0 & 0 & 2 & 0.43( \pm 0.58)\end{array}$

Psoas major L5-S1

\begin{tabular}{lllllllll} 
Right & 13 & 8 & 2 & 0 & 0 & 0 & 2 & $0.52( \pm 0.66)$ \\
Left & 13 & 8 & 2 & 0 & 0 & 0 & 2 & $0.52( \pm 0.66)$ \\
\hline
\end{tabular}


Table 3. Grade of Fatty Infiltration in Chronic LBP patient

\begin{tabular}{|c|c|c|c|c|c|c|c|c|}
\hline \multirow{2}{*}{ Muscle And Level } & \multicolumn{5}{|c|}{ Grade of fatty infiltration ( $\mathrm{n}$ of samples) } & \multirow[t]{2}{*}{ Min. Grade } & \multirow[t]{2}{*}{ Max.Grade } & \multirow[t]{2}{*}{ Mean (SD) } \\
\hline & 0 & 1 & 2 & 3 & 4 & & & \\
\hline \multicolumn{9}{|l|}{ Erector spinae L3-4 } \\
\hline Right & 2 & 22 & 5 & 0 & 0 & 0 & 2 & $1.10( \pm 0.48)$ \\
\hline Left & 2 & 21 & 6 & 0 & 0 & 0 & 2 & $1.13( \pm 0.51)$ \\
\hline
\end{tabular}

Erector spinae L4-5

$\begin{array}{lllllllll}\text { Right } & 0 & 20 & 9 & 0 & 0 & 1 & 2 & 1.31( \pm 0.47) \\ \text { Left } & 0 & 20 & 9 & 0 & 0 & 1 & 2 & 1.31( \pm 0.47)\end{array}$

Erector spinae L5-S1

$\begin{array}{lllllllll}\text { Right } & 0 & 15 & 12 & 2 & 0 & 1 & 3 & 1.55( \pm 0.63) \\ \text { Left } & 0 & 15 & 10 & 3 & 1 & 1 & 4 & 1.65( \pm 0.81)\end{array}$

Multifidus L3-4

$\begin{array}{lllllllll}\text { Right } & 0 & 14 & 3 & 2 & 0 & 1 & 3 & 1.58( \pm 0.62) \\ \text { Left } & 0 & 13 & 14 & 2 & 0 & 1 & 3 & 1.62( \pm 0.62)\end{array}$

Multifidus L4-5

$\begin{array}{lllllllll}\text { Right } & 0 & 12 & 14 & 3 & 0 & 1 & 3 & 1.68( \pm 0.66) \\ \text { Left } & 0 & 11 & 15 & 3 & 0 & 1 & 3 & 1.72( \pm 0.64)\end{array}$

Multifidus L5-S1

$\begin{array}{lllllllll}\text { Right } & 0 & 9 & 13 & 7 & 0 & 1 & 3 & 1.93( \pm 0.75) \\ \text { Left } & 0 & 9 & 13 & 6 & 1 & 1 & 4 & 1.96( \pm 0.82)\end{array}$

Psoas major L3-4

$\begin{array}{lllllllll}\text { Right } & 1 & 13 & 15 & 0 & 0 & 0 & 2 & 1.48( \pm 0.57) \\ \text { Left } & 1 & 13 & 14 & 1 & 0 & 0 & 3 & 1.51( \pm 0.63)\end{array}$

Psoas major L4-5

$\begin{array}{lllllllll}\text { Right } & 2 & 6 & 21 & 0 & 0 & 0 & 2 & 1.65( \pm 0.61) \\ \text { Left } & 2 & 6 & 20 & 1 & 0 & 0 & 3 & 1.68( \pm 0.66)\end{array}$

Psoas major L5-S1

$\begin{array}{lllllllll}\text { Right } & 1 & 8 & 19 & 1 & 0 & 0 & 3 & 1.68( \pm 0.60) \\ \text { Left } & 1 & 7 & 18 & 2 & 0 & 0 & 3 & 1.75( \pm 0.64)\end{array}$




\section{Discussion}

The role of the paravertebral muscles in patients with LBP remains controversial. A reduction in spinal muscle crosssectional area on MRI and CT, with or without reduced muscle density on CT, may be found in patients with acute and chronic LBP, as well as LBP following surgery. In degeneration, the increased range of motion between the adjacent spinal segments may induce increased stress to the muscular structures that can damage muscle directly (myogenic atrophy), or indirectly by traumatic denervation (neurogenic atrophy). (Bierry et al., 2008)

The morphological changes associated with muscular degeneration include fat infiltration and reduced muscle mass. These changes can be evaluated in CT or MRI with various quantitative and qualitative methods, such as Goutallier classification, simplified 3 grade system, or correlation with adjacent vertebral body. All methods have their own strength and limitations. (Upadhyay and Toms, 2015) In this study, we measured the fatty infiltration of paraspinal muscles using Goutallier calssification. This method was first used as a tool to classified rotator cuff fatty infiltration, with prognostic utility and treatment evaluation. (Somerson et al., 2016) Battaglia et al. then used this classification system to assessed the grade of fatty infiltration in lumbar multifidus muscle. In their study, the Goutallier is proven to be a reliable tool in grading fatty infiltration of multifidus with significant correlation with quantitative measurement and good inter-observer reliability. (Battaglia et al., 2014)

The results shown in table 2 and 3 are the analysis of fatty infiltration in low back pain patients after the exclusion of trauma, infections, and neoplasms of spine. We found higher fatty infiltration grade in the chronic group. In a previous study by Wan et al., they measured the fatty infiltration by percentage of fat content in paraspinal muscles' cross sectional area of patients with unilateral chronic and acute LBP. The results shown reduction in cross sectional area with multisegmental atrophy in chronic patients. While the atrophy in acute stage may due to disuse, the chronic stage probably related to the compensatory mechanism of contralateral side. However, some theory also suggested that denervation has an important role in association with radiculopathy. (Wan et al., 2015)

Several studies also suggested the association of chronic LBP and changes in paraspinal muscles. Reduced muscle size and increased fat content is a sign of degeneration. However, Mengiardi et al. evaluated that no significant diffenece in semiquantitative assessment of fat content between control group and chronic LBP patients. Their study suggested that magnetic resonance (MR) spectroscopy will depict earlier stage of fatty infiltration, because MR spectroscopy demonstrates a significantly higher fat content in the multifidus muscle. (Mengiardi et al., 2006)

We also found that the fatty infiltration grade increase at level L5-S1, the lowest level of our evaluation. In a prospective study by Crawford et al., they found that although there is no difference of fat signal in L1, L2, and L3 levels, the highest fat signal were found at level L4-L5. (Crawford et al., 2016) This finding suggested a craniocaudal increase of fat signal, also the relationship of muscle quality with shape and function of spine.

The limitation of our study is the lack of control group to performed a analytic study, to determine association of fatty infiltration and onset of LBP. We also suggested a prospective study to determine whether the fatty degeneration occurred before the LBP or vice versa.

\section{Conclusion}

In this study, fatty infiltration in erector spinae, multifidus, and psoas major showed increased grade in chronic duration of LBP. Both in acute and chronic LBP patients the fatty infiltration tends to be higher in level L5-S1, the lowest level of evaluation. We hope the interpretation of fatty infiltration in paraspinal muscle will be a routine investigation in lumbosacral MRI.

Further studies are needed to determine any association with age, body mass index, or pain duration, also a prospective study to investigate the influence of lifestyle.

\section{Acknowledgment}

A sincere gratitude to all my teachers, colleagues, family, and all the patients included in this study.

\section{References}

Battaglia, P. J. et al. (2014) 'Reliability of the Goutallier classification in quantifying muscle fatty degeneration in the lumbar multifidus using magnetic resonance imaging', Journal of Manipulative and Physiological Therapeutics. Mosby Inc., 37(3), pp. 190-197. doi: 10.1016/j.jmpt.2013.12.010. 
Beneck, G. J. and Kulig, K. (2012) 'Multifidus atrophy is localized and bilateral in active persons with chronic unilateral low back pain', Archives of Physical Medicine and Rehabilitation. W.B. Saunders, 93(2), pp. 300-306. doi: 10.1016/j.apmr.2011.09.017.

Bhadresha, A., Lawrence, O. J. and McCarthy, M. J. H. (2016) 'A Comparison of Magnetic Resonance Imaging Muscle Fat Content in the Lumbar Paraspinal Muscles with Patient-Reported Outcome Measures in Patients with Lumbar Degenerative Disk Disease and Focal Disk Prolapse', Global spine journal. 2016/04/28. Georg Thieme Verlag KG, 6(4), pp. 401-410. doi: 10.1055/s-0036-1583290.

Bierry, G. et al. (2008) 'Disorders of paravertebral lumbar muscles: From pathology to cross-sectional imaging', Skeletal Radiology, pp. 967-977. doi: $10.1007 / \mathrm{s} 00256-008-0494-8$.

Crawford, R. J. et al. (2016) 'Age- and level-dependence of fatty infiltration in lumbar paravertebral muscles of healthy volunteers', American Journal of Neuroradiology. American Society of Neuroradiology, 37(4), pp. 742-748. doi: 10.3174/ajnr.A4596.

Danneels, L. A. et al. (2000) 'CT imaging of trunk muscles in chronic low back pain patients and healthy control subjects', European Spine Journal, 9(4), pp. 266-272. doi: 10.1007/s005860000190.

Fortin, M. and Macedo, L. G. (2013) Multifidus and Paraspinal Muscle Group Cross-Sectional Areas of Patients With Low Back Pain and Control Patients: A Systematic Review With a Focus on Blinding Background. Several studies have investigated differences in paraspinal muscle. Available at: www.Cochrane.org].

Hildebrandt, M. et al. (2017) 'Correlation between lumbar dysfunction and fat infiltration in lumbar multifidus muscles in patients with low back pain', BMC Musculoskeletal Disorders. BMC Musculoskeletal Disorders, 18(1), pp. 1-9. doi: 10.1186/s12891-016-1376-1.

Kalichman, L., Carmeli, E. and Been, E. (2017) 'The Association between Imaging Parameters of the Paraspinal Muscles, Spinal Degeneration, and Low Back Pain', BioMed Research International. Hindawi Limited. doi: 10.1155/2017/2562957.

Kjaer, P. et al. (2007) 'Are MRI-defined fat infiltrations in the multifidus muscles associated with low back pain?', BMC Medicine, 5, pp. 1-10. doi: $10.1186 / 1741-7015-5-2$.

Mengiardi, B. et al. (2006) 'Fat content of lumbar paraspinal muscles in patients with chronic low back pain and in asymptomatic volunteers: Quantification with MR spectroscopy', Radiology, 240(3), pp. 786-792. doi: 10.1148/radiol.2403050820.

Sitthipornvorakul, E. et al. (2011) 'The association between physical activity and neck and low back pain: A systematic review', European Spine Journal, pp. 677-689. doi: 10.1007/s00586-010-1630-4.

Somerson, J. S. et al. (2016) 'Classifications in Brief: Goutallier Classification of Fatty Infiltration of the Rotator Cuff Musculature', Clinical Orthopaedics and Related Research. Springer New York LLC, 474(5), pp. 1328-1332. doi: 10.1007/s11999-015-4630-1.

Upadhyay, B. and Toms, A. P. (2015) 'CT and MRI evaluation of paraspinal muscle degeneration', in European Society of Radiology ECR, pp. C-2114. doi: 10.1594/ecr2015/C-2114.

Wan, Q. et al. (2015) 'MRI assessment of paraspinal muscles in patientswith acute and chronic unilateral low back pain', British Journal of Radiology. British Institute of Radiology, 88(1053). doi: 10.1259/bjr.20140546. 